\title{
Early Functional Outcome of Posterior Spinal Decompression for Lumbar Spinal Stenosis at a Tertiary Health Institution, South East Nigeria
}

\author{
Obiora Nonso Muoghalu*, Cajetan U. Nwadinigwe, Emmanuel C. Iyidobi, Ndubuisi N. Duru, \\ Udo E. Anyaehie, Ikechukwu C. Okwesili \\ Department of Orthopaedics, National Orthopaedic Hospital, Enugu, Nigeria \\ Email: *obioramuoghalu@yahoo.com, info@nohenugu.org.ng,dreciyidobi@yahoo.com,drneduru@yahoo.com, \\ udo179@yahoo.com, ikeokwesili@gmail.com
}

How to cite this paper: Muoghalu, O.N., Nwadinigwe, C.U., Iyidobi, E.C., Duru, N.N., Anyaehie, U.E. and Okwesili, I.C. (2018) Early Functional Outcome of Posterior Spinal Decompression for Lumbar Spinal Stenosis at a Tertiary Health Institution, South East Nigeria. Journal of Biosciences and Medicines, 6, $1-14$.

https://doi.org/10.4236/jbm.2018.67001

Received: May 30, 2018

Accepted: July 3, 2018

Published: July 6, 2018

Copyright (c) 2018 by authors and Scientific Research Publishing Inc. This work is licensed under the Creative Commons Attribution International License (CC BY 4.0).

http://creativecommons.org/licenses/by/4.0/

\begin{abstract}
Background: Surgical treatment of lumbar spinal stenosis by posterior spinal decompression may be indicated if non-surgical management for the symptoms of low back and lower limbs radicular pains is unsuccessful and/or in patients with persisting or worsening neurological deficits. It has been reported to be an effective treatment modality in well selected patients. This procedure is however not without possible complications which can adversely affect the outcome of treatment in the affected patients. This prospective study was therefore undertaken to evaluate the early functional outcome of posterior spinal decompression for lumbar spinal stenosis at our health institution. Method: All patients with symptomatic lumbar spinal stenosis admitted for posterior spinal decompression and who met the inclusion criteria were recruited with their written informed consent. The patients' pain severity and functional disability were assessed preoperatively with visual analogue scale (VAS) and Oswestry Disability Index (ODI). The VAS and ODI were also used to reassess the patients postoperatively, at 2 weeks, 6 weeks and 12 weeks respectively. All intraoperative and/or postoperative complications were documented and the results were analyzed. Results: The patients' mean preoperative lower back pain and leg pain VAS score was $8.26 \pm 1.46$ while the mean preoperative ODI was $62.4 \% \pm 13.56$. The commonest combination of spinal decompressive procedure done in the patients was laminectomy + foraminotomy in 10 (25\% patients). The most common decompressed spinal level was L4/L5 (89.7\%); while almost equal number of patients had either one spinal level or two-spinal level decompression ( $43.6 \%$ and $46.1 \%$ respectively). Postoperative pain assessment showed a mean VAS of $3.79 \pm 1.15,2.55 \pm 1.27$ and $2.00 \pm 1.41$ at 2 weeks, 6 weeks and 12 weeks respectively $(p=0.000)$.
\end{abstract}


Functional outcome assessment with ODI was $34 \% \pm 11.79 \%, 24 \% \pm 10.75 \%$ and $18.12 \% \pm 10.61 \%$ at 2 weeks, 6 weeks and 12 weeks respectively ( $p=$ $0.000)$. The commonest surgical complication seen was dura tear which occurred in nine patients $(23.1 \%)$. Conclusion: There was significant reduction in low back and radicular pains with consequent functional improvement in majority of the patients who had posterior spinal decompression for lumbar spinal stenosis at our health institution. There were few complications of which dura tear was the commonest.

\section{Keywords}

Early Functional Outcome, Lumbar Spinal Stenosis, Posterior Spinal Decompression, Complications

\section{Introduction}

Lumbar spinal stenosis is recognized as a frequent cause of low back and lower extremities pain; it has also been recognized as a common cause of disability in adults requiring surgery for its treatment [1] [2] [3] [4].

Lumbar spinal stenosis as defined by Verbiest is the narrowing of the central spinal canal, lateral recess or the neural foramen [5]. These stenotic changes usually cause neural compression that presents clinically as leg and low back pain, gait abnormalities as well as other neurological deficits which could cause severe functional limitation in the affected patients [5] [6].

The goal of surgical treatment in these patients is to alleviate the pain, halt and hopefully reverse neurological deterioration, maintain the stability of the spine and ultimately improve the patients' general function which is usually affected by this pathology [1] [2] [3] [4] [6].

Posterior spinal decompression (PSD) has been reported as an effective procedure and associated with improvement of spinal claudication symptoms, low back and radicular pains in the patients with spinal stenosis [4] [7]. Prospective randomized trials, particularly the Spine Patient Outcome Research Trial (SPORT) study, did provide compelling evidence that decompression surgery is an effective treatment that provides pain relief and functional improvements in patients with lumbar spinal stenosis [3].

The "success" rate of decompression surgery in many parts of the world varies considerably, with functional improvement ranging between 58\% and 69\%, participant satisfaction ranging from $15 \%$ to $81 \%$ and degree of pain relief varying between studies [8].

This study therefore, is to evaluate the early outcome in patients with lumbar spinal stenosis that had posterior spinal decompression in our hospital with respect to function and pain relief using the Oswestry Disability Index (ODI) and the Visual Analogue Scale (VAS), identify the nature and incidence of complications associated with the surgical procedure and recommend measures to im- 
prove the outcome.

\section{Methodology}

This was a prospective study conducted in the spine unit of the National Orthopaedic Hospital Enugu, South East Nigeria. Ethical approval was granted by the institution's medical research ethics committee and a written informed consent received from all the participants in the study.

All consecutive symptomatic patients with lumbar spinal stenosis confirmed by MRI and admitted for posterior lumbar spinal decompression from October 2015 to November 2016 unless excluded were recruited for the study.

The exclusion criteria were: Patients with greater than Meyerding grade 1 spondylolisthesis, associated degenerative scoliosis of more than $30^{\circ}$, patients with tandem stenosis, patients with previous back surgery and patients who had concomitant instrumented spinal fusion.

A detailed evaluation of patients' symptoms and physical examination findings were done and documented. The severity of the patients' low back and leg pain was assessed and graded with the visual analogue scale (VAS), while the preoperative functional status was evaluated with the Oswestry Disability Index (ODI).

All the patients had posterior spinal decompression under general anaesthesia with or without non instrumented spinal fusion. The exact nature and extent of the surgery in each patient were dependent on the intraoperative findings and ranged from simple laminectomy to additional discectomy and/ or foraminotomy then to intertransverse fusion with autogenous bone grafts in some of the patients. The exact level(s) decompressed and any intraoperative complication(s) were documented. The Patients were monitored for post-operative complications and were discharged to the outpatient clinic after two weeks. The VAS and ODI were used to reevaluate the patients at two weeks, six weeks and 3 months postoperative intervals.

The data was analyzed with SPSS 20 , paired sample T test was used to analyze the significance of the difference in the mean of continuous dependent variables as seen at the different intervals. Results were presented in texts, table, figures and graphs. Test for significance was set at $p<0.05$.

\section{Results}

\subsection{Patients' Demographics}

A total of thirty-nine patients who had posterior spinal decompression for lumbar spinal stenosis were enrolled for the study. There were twenty males (51.3\%) and nineteen females (48.7\%) and the mean age was $53 \pm 9.92$ years (Figure 1). The mean duration of the patients' symptoms was $3.71 \pm 3.47$ years (Table 1).

Thirty-eight patients were seen at 6 weeks and thirty-seven at 12 weeks follow up assessment with two of the patients lost to follow up. 
Table 1. Distribution of duration of patients' symptoms.

\begin{tabular}{ccc}
\hline Duration of symptoms & Frequency & Percent \\
\hline$<1$ year & 8 & 20.5 \\
$1-3$ years & 14 & 35.9 \\
$4-6$ years & 10 & 25.6 \\
7 - 9 years & 4 & 10.3 \\
10 years and above & 3 & 7.7 \\
Total number of patients & 39 & 100 \\
\hline
\end{tabular}

\section{Age distribution}

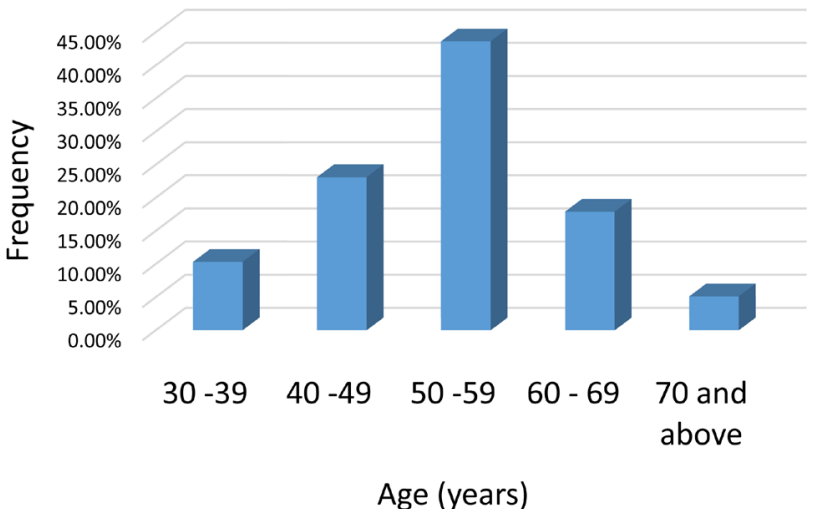

Figure 1. Age distribution.

All the patients have tried one form or a combination of non-surgical treatment including un-orthodox therapy before spinal decompression. The commonest type of previous treatment received was use of oral and parenteral analgesics which were mostly non-steroidal anti-inflammatory drugs (NSAIDS) and opioids (Tramadol) (Table 2).

\subsection{Preoperative VAS and ODI}

The mean preoperative VAS score was $8.26 \pm 1.46$ (Table 3). The least score was 5 and was seen in only two patients (5.1\%) The remaining patients had a score of 6 or above before spinal decompression.

The mean pre-operative ODI was $62.35 \% \pm 13.55 \%$ (Table 4). Only two patients (5.1\%), had pre-operative ODI of "moderate disability", the rest had ODI of "severe disability" or worse.

\subsection{Surgical Procedures}

Decompressive laminectomy was done in all the patients, while additional procedures were done in majority of them depending on the intraoperative findings. Twelve patients (30.8\%), in addition to the different decompressive procedures done, had concomitant inter-transverse fusion with autogenous bone graft (Table 5). 
Table 2. Previous treatments received by the patients.

\begin{tabular}{|c|c|c|}
\hline Previous treatment & Frequency & Percent \\
\hline Analgesics only & 20 & 51.3 \\
\hline Analgesics + Physiotherapy & 13 & 33.3 \\
\hline Analgesics + Epidural injection & 1 & 2.6 \\
\hline Analgesics + Traditional treatment & 3 & 7.7 \\
\hline Analgesics + Physiotherapy + Traditional treatment & 2 & 5.1 \\
\hline Total & 39 & 100 \\
\hline
\end{tabular}

Table 3. Patients' VAS scores preoperatively and at follow-up visits.

\begin{tabular}{cccccc}
\hline Pain rating & Pre-op & Discharge & 6 weeks post op & 12 weeks post op & $P$ value \\
\hline 0 & $0(0)$ & $0(0)$ & $0(0)$ & $4(10.8)$ & 0.000 \\
1 & $0(0)$ & $0(0)$ & $5(13.2)$ & $11(29.7)$ & \\
2 & $0(0)$ & $2(5.1)$ & $19(50.0)$ & $12(32.4)$ & \\
3 & $0(0)$ & $17(43.6)$ & $7(18.4)$ & $5(13.5)$ & \\
4 & $0(0)$ & $11(28.20$ & $4(10.5)$ & $1(2.7)$ & \\
5 & $2(5.1)$ & $7(17.9)$ & $2(5.3)$ & $4(10.8)$ & $0(0)$ \\
6 & $4(10.3)$ & $1(2.6)$ & $0(0)$ & $0(0)$ & $0(0)$ \\
7 & $4(10.3)$ & $0(0)$ & $1(2.6)$ & $0(0)$ & \\
8 & $10(25.6)$ & $1(2.6)$ & $0(0)$ & $0(0)$ & \\
9 & $10(25.6)$ & $0(0)$ & $0(0)$ & $0(100)$ & \\
10 & $9(23.1)$ & $0(0)$ & $0(0)$ & $2.00 \pm 1.41$ &
\end{tabular}

Table 4. Patients' ODI preoperatively and at follow-up visits.

\begin{tabular}{cccccc}
\hline ODI Category & $\begin{array}{c}\text { Pre op } \\
\mathrm{N}(\%)\end{array}$ & $\begin{array}{c}\text { Discharge } \\
\mathrm{N}(\%)\end{array}$ & $\begin{array}{c}6 \text { weeks post op } \\
\mathrm{N}(\%)\end{array}$ & $\begin{array}{c}12 \text { weeks post op } \\
\mathrm{N}(\%)\end{array}$ & $P$-value \\
\hline $\begin{array}{c}\text { Minimal disability } \\
(0 \%-20 \%)\end{array}$ & $0(0)$ & $4(10.3)$ & $19(50.0)$ & $27(73.0)$ & 0.000 \\
$\begin{array}{c}\text { Moderate disability } \\
(21 \%-40 \%)\end{array}$ & $2(5.1)$ & $22(56.4)$ & $16(42.1)$ & $8(21.6)$ & \\
$\begin{array}{c}\text { Severe disability } \\
(41 \%-60 \%)\end{array}$ & $23(59.0)$ & $12(30.8)$ & $3(7.9)$ & $2(5.4)$ & \\
$\begin{array}{c}\text { Crippled } \\
(61 \%-80 \%)\end{array}$ & $9(23.1)$ & $1(2.6)$ & $0(0)$ & $0(0)$ & \\
$\begin{array}{c}\text { Bed bound or } \\
\text { exaggerating } \\
\text { symptoms } \\
(81 \%-100 \%)\end{array}$ & $5(12.8)$ & $0(0)$ & $0(0)$ & $0(0)$ & \\
$\begin{array}{c}\text { Total number of } \\
\text { patients }\end{array}$ & $39(100)$ & $39(100)$ & $38(100)$ & $37(100)$ & \\
$\quad$ Mean ODI & $62.35 \pm 13.56$ & $34 \pm 11.79$ & $24 \pm 10.75$ & $18.12 \pm 10.61$ & \\
\hline
\end{tabular}


Table 5. Distribution of the types of surgery done in the patients.

\begin{tabular}{lcc}
\multicolumn{1}{c}{ Type of surgery } & Frequency & Percent \\
\hline Laminectomy only & 7 & 17.9 \\
Laminectomy + Foraminotomy & 10 & 25.6 \\
Laminectomy + Discectomy & 4 & 10.3 \\
Laminectomy + Foraminotomy + Discectomy & 6 & 15.4 \\
$\begin{array}{l}\text { Laminectomy + Foraminotomy + Discectomy + } \\
\text { Inter-transverse fusion with autogenous bone graft }\end{array}$ & 2 & 5.1 \\
$\begin{array}{l}\text { Laminectomy + Foraminotomy + Inter-transverse } \\
\text { fusion with autogenous bone graft }\end{array}$ & 7 & 17.9 \\
$\begin{array}{l}\text { Laminectomy + Inter-transverse fusion with } \\
\text { autogenous bone graft }\end{array}$ & 3 & 7.7 \\
\multicolumn{1}{c}{ Total } & 39 & 100 \\
\hline
\end{tabular}

The most common decompressed spinal level in the patient was L4/L5 (89.7\%). None of the patients had L1/L2 decompression (Figure 2).

Most of the patients had either a 1-level or 2-level decompression. There were however four cases of 3-level spinal decompression in four patients (10.3\%) (Figure 3).

\subsection{Postoperative VAS and ODI}

Pain assessment was done at discharge, 6 weeks and 12 weeks post-operative visits. The mean score was $3.79 \pm 1.15,2.55 \pm 1.27$ and $2.00 \pm 1.41$ respectively. The $p$ value for the statistical test for the difference in mean at each interval was 0.000 , which was statistically significant. Maximum VAS at 12 weeks was 5 and was noted only in four patients (10.8\%).

Serial evaluation of the patients following surgery with ODI at discharge, 6 weeks and 12 weeks showed a mean ODI of $34 \% \pm 11.79 \%, 24 \% \pm 10.75 \%$ and $18.12 \% \pm 10.61 \%$ respectively. Statistical test of the ODI mean score difference at the different follow up intervals was statistically significant $(p=0.000)$ At 12 weeks, post-operative visit evaluation only two patients (5.4\%) still had severe disability, none of the patients were "crippled or bed bound".

\subsection{Complications}

The commonest complication seen was dura tear in nine patients $(23.1 \%)$. The tears were all repaired intraoperatively and no case of postoperative cerebrospinal fluid leakage was recorded (Figure 4).

\section{Discussion}

The mean VAS score in the patients was $8.26 \pm 1.46$. This shows that the pain was quite severe. This figure is slightly higher than that from the studies by $\mathrm{Yu}$ kawa et al. [9] and Gelalis et al. [10] which was 7.1 and 7.5 respectively. Sanderson et al. [11] reported a pre-operative pain score of 6.6 while Kwon et al. series 


\section{Frequency of decompression at different spinal levels}
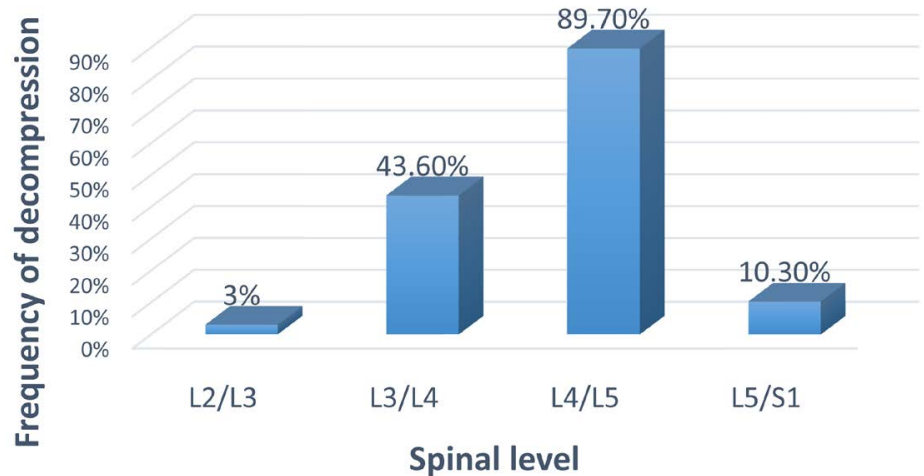

Figure 2. Frequency of decompression at different spinal levels.

\section{Distribution of number of spinal level(s) decompressed in individual patients}

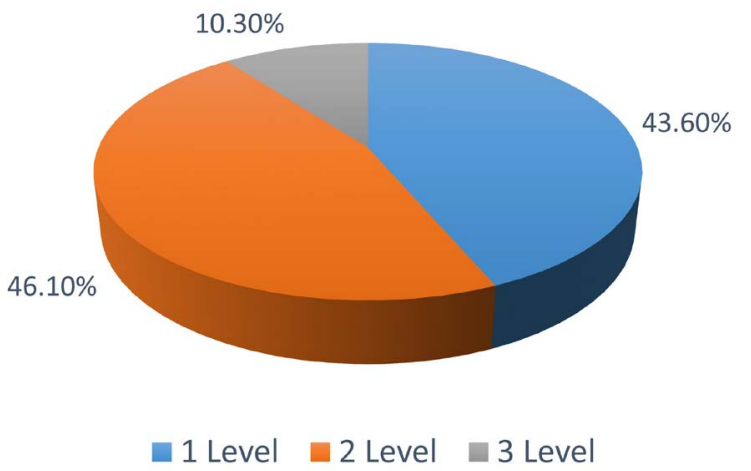

Figure 3. Distribution of number of spinal level(s) decompressed in individual patients.

\section{Distribution of Surgical Complications}

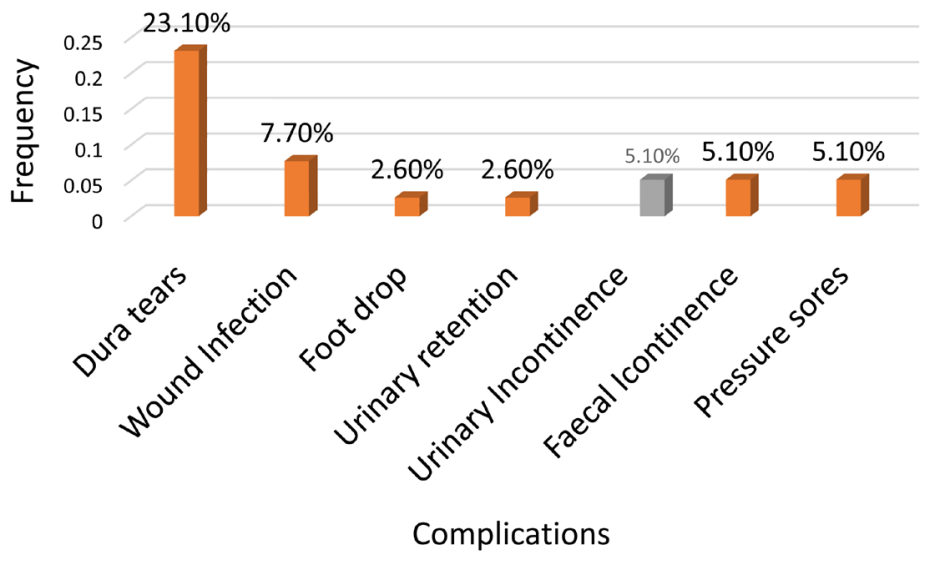

Figure 4. Distribution of surgical complications.

[12], had a preoperative mean VAS of 5.5. Bojanic et al. had a pre-operative pain mean score of 4 in the patients that had surgery for lumbar spinal stenosis [13]. 
The higher mean pain score in this study could be due to the advanced nature of the pathology in the population due to late presentation, and/or late acceptance of surgical treatment; as many of the patients refused spinal decompression until their pain became unbearable to them.

The mean pre-operative Oswestry disability index score of the patients was $62.5 \%$ which is interpreted as "crippled". This further underscores the severity of the pain and disability occasioned by this pathology in our patients prior to surgical intervention as many of them could no longer effectively carry out their activities of daily living necessitating their presentation for surgery. Gelalis et al. [10], had a slightly lower ODI of $60.5 \%$ in the patients they admitted for decompressive laminectomy, while Yukawa et al. and Kwon et al. in their studies reported a pre-operative mean ODI of $57.4 \%$ and $42.8 \%$ respectively in their patients [9] [10].

The study showed that only seven patients (17.9\%) had laminectomy procedure only, during the course of the decompressive surgery, the rest of the patients had other procedures in addition to laminectomy. The patients who had only laminectomy; were those whose clinical presentation, radiological and intraoperative findings were suggestive of a central canal stenosis from severely thickened ligamentum flavum with less significant lateral recess and/or foraminal stenosis. Twenty-five patients (64.1\%) in addition to other procedures had foraminotomy, this is more than the figure of eleven (27.5\%) reported by Postacchini et al. [14]. Twelve patients (30.8\%) in this study had discectomy in addition to other procedures while in another study by Postacchini et al. [15], discectomy was performed in $20 \%$ of the patients. Sanderson et al. [11], however, reported that none of the 31 patients in their study with degenerative spinal stenosis had discectomy. Concomitant inter-transverse process fusion with autogenous bone graft was done in $30.8 \%$ of the patients, the figure is similar to $30 \%$ noted in the study by Postacchini et al. [15], in contrast however, Sanderson et al. [11], submitted that none of the patients who had decompression for degenerative lumbar spinal stenosis had fusion. The inter-transverse fusion with autogenous bone graft was done in all the patients with associated spondylolisthesis and in some of the patients who had more extensive decompression in order to prevent possible postoperative instability. Harkowitz et al. had demonstrated that inter-transverse fusion is associated with significant reduction in postoperative progression of listhesis and instability with consequent improvement in clinical outcome in patients who had concomitant spondylolisthesis and/or when the decompressive procedures may have compromised the spine stability [16].

There were slightly more 2-level than single level spinal decompression in our patients ( $46.1 \%$ and $43.6 \%$ respectively), while fewer number (10.3\%) had 3-level decompression. The choice of the level to be decompressed was made from both clinical and radiological findings. The less inclination by the surgeons for a multilevel decompression in some of the patients with multilevel spinal stenosis, could be to reduce the risk of possible attendant instability in the absence of in- 
strumented fusion.

In contrast to this study, a few other studies have reported more single level than two or multilevel decompression [12] [17] [18].

L4/L5 was the most commonly decompressed level in the patients (89.7\%). This agrees with the pattern observed by Leonardi et al. [19], which had L4/L5 as the most frequent decompressed level (66.7\%). In the same vein, Kwon et al. noted similar pattern with frequency of $79 \%$ and $39 \%$ for L4/L5 and L3/L4 respectively [12].

Pain assessment done at discharge, 6 weeks and 12 weeks post-operative intervals; had a mean VAS score of 3.79, 2.55 and 2.00 respectively. Paired sample t-test was used to test the difference between the pre-operative mean VAS and the post-operative mean VAS at the different follow -up intervals. This was found to be statistically significant $(p=0.000)$. However the study noted that though there was statistically significant reduction of pain in all the patients, four patients $(10.8 \%)$ still had what they considered worrisome pain at 12 weeks with VAS of 5 , though they acknowledged a reduction in their pain severity.

Similarly, the mean post-operative ODI, at discharge, 6 weeks and 12 weeks post-operative intervals was found to be $34 \%, 24 \%$ and $18.12 \%$ respectively. In the same vein, statistical analysis of the difference in the mean from the pre-operative to post-operative ODI values was equally significant at each inter$\operatorname{val}(p=0.000)$. It is worthy to note that though majority of the patients $(73 \%)$ had only "minimal disability" (ODI $=0 \%-20 \%$ ) at 12 weeks follow -up, two patients $(5.4 \%)$ still had "severe disability" (ODI $=41 \%-60 \%)$. A graphical plot of the of the patients' mean VAS and ODI scores at the different intervals, showed that the greatest improvement was recorded during the first post-operative assessment at 2 weeks as evidenced by the steepness of the graph (Figure 5, Figure 6); while subsequent assessments at 6 weeks and 12 weeks though showed significant progressive improvement, were not as marked as the improvement seen at the more immediate postoperative period.

This outcome is comparable to some previous studies on posterior spinal decompression for lumbar spinal stenosis. Postachinni et al. [15], in their study reported that $81 \%$ of the patients had excellent outcome after spinal decompression for lumbar spinal stenosis while Sanderson et al. [11], noted that $64.5 \%$ of patients in their series had no significant pain after surgery. A study in Tema, Ghana by Andrews et al. also reported a significant difference in the preoperative and post-operative pain scores after decompression [20]. The patients in the study by Kwon et al. [12], had a mean postoperative VAS and ODI of 1.3 and $19.0 \%$, while Yukawa et al. [9] observed a mean of $2.3 \%$ and $21.1 \%$; this is quite similar to the VAS and ODI scores of $2.0 \%$ and $18.1 \%$ respectively, at 12 weeks post-operative assessment of our patients. Gelalis et al. reported less improvement in the pain and disability scores in their patients, with VAS and ODI of 3.5 and $36.8 \%$ respectively at 3 month postoperative assessment [10]. 


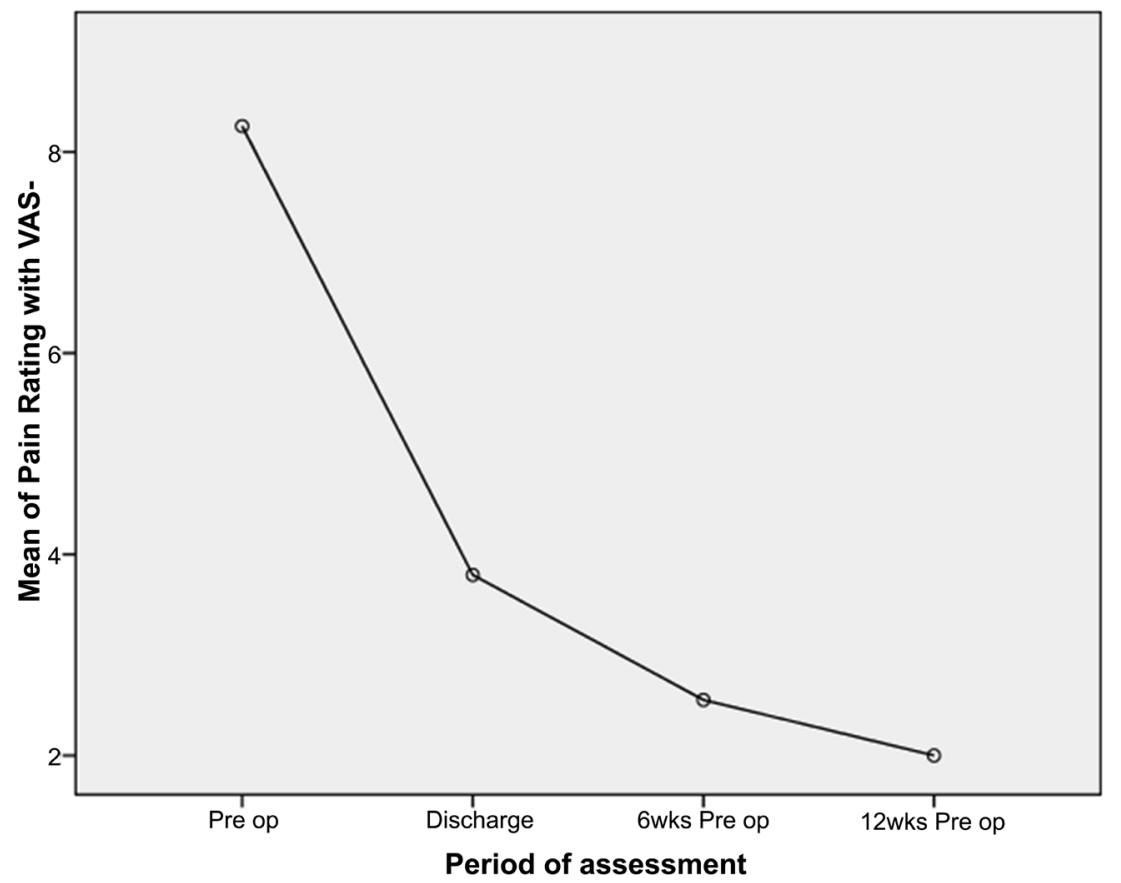

Figure 5. A graph plot of the mean VAS scores from preoperative to 12 weeks postoperative visits.

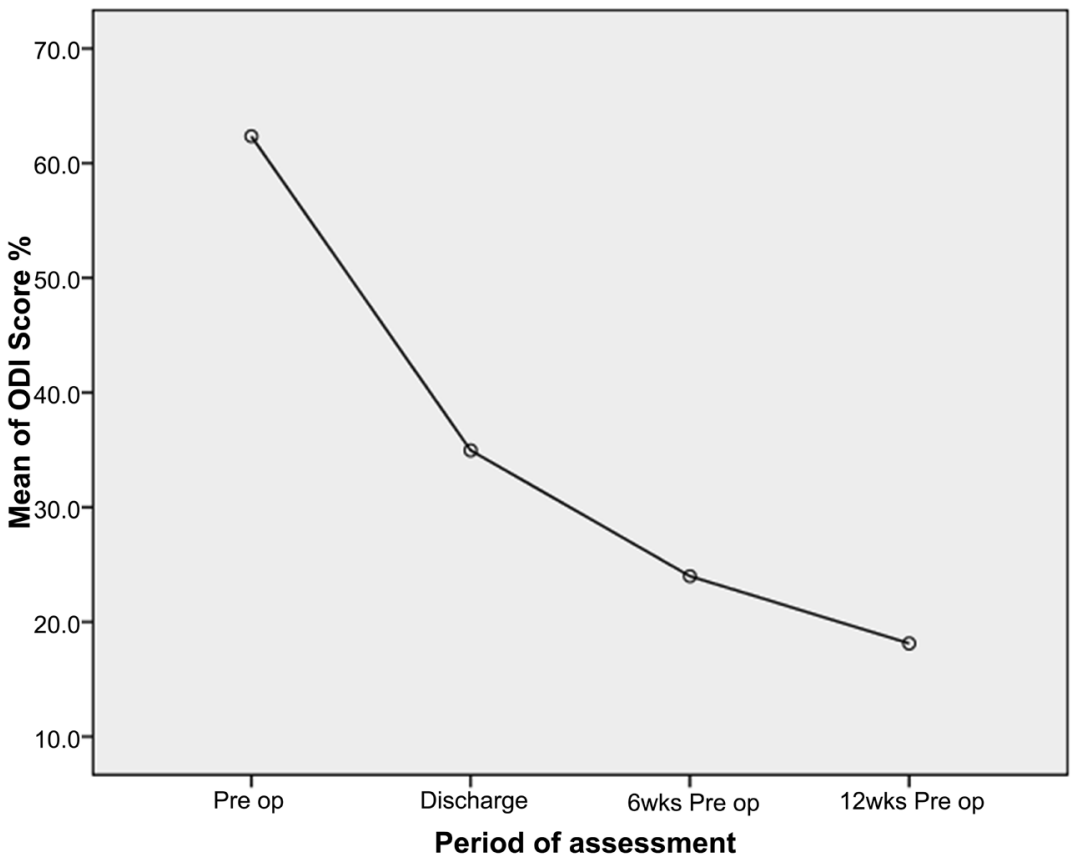

Figure 6. A graph plot of the patients' mean ODI from preoperative to 12 weeks postoperative visits.

The significant bothersome pain (VAS-5) in four of our patients even at 12 weeks after surgery, could be due to inadequate decompression in the patients; as some had significant multilevel stenosis and could have benefited from a more extensive decompression and instrumented spinal fusion to prevent possi- 
ble attendant instability. Sanderson et al. [11] reported poor results in six patients who despite weeks after decompression, still had a mean VAS of 7.1; the outcome they attributed to long duration of their symptomsprior to treatment as the mean duration of symptoms in the 6 patients was 10.4 years. In contrast however, the four patients in our study with bothersome symptoms at 12 weeks had a mean duration of symptoms of 2.3 years.

Some surgical complications were noted in this study. Dura tear was the commonest (23.1\%) and usually occurred when the ligamentum flavum was being teased off the dura tissue especially in patients with avidly adherent thickened ligamentum flavum. The lack of finer range of surgical instruments might have also contributed to the increased incidence of dura tears in the patients. The tears were all repaired immediately with non-absorbable suture (prolene 4/0). None of the patients with dura tear had persisting CSF drainage post operatively. This finding is similar to the report by Kwon et al. [12], who in their series had dura tear as the commonest complication though at $10.5 \%$, it was less common. Okuda et al., also reported dura tear as the commonest complication in 251 patients with lumbar spinal stenosis who had decompression; 19 (7.6\%) had dura tear [21]. Postachinni et al. however, had only one case of dura tear in their patients [15].

Surgical site infection was recorded in three patients (7.7\%), though they were all superficial and all healed with dressing changes and antibiotics. Staphylococcus aureus was cultured in two patients while the other wound yielded coliforms on culture. Two of the patients with wound infections also were diabetics and that may have increased the risk of surgical site infection in them. Kanafani et al. in a 3-year study in Lebanon among 997 patients, reported a surgical site infection of $2.7 \%$. They also noted that staphylococcus aureus was the commonest organism implicated and many of the infections occurred in diabetic patients [22]. Weinstein et al. also in a large series had infection rate of 1.9\% [23]. Okuda et al. had only one case of surgical site infection though a deep infection which was observed in a diabetic and renal failure patient [21].

One patient (2.6\%) had right foot drop after decompression probably due to L4 root injury. The patient was managed with ankle foot orthosis (AFO) and physiotherapy postoperatively. Though there has been some improvement, the patient still has residual ankle weakness at 3 months postoperative review. Postachinni et al. [15] also reported nerve injury complicating posterior spinal decompression. They noted postoperative L5 neural deficit in two patients and L4 injury in one patient. Okuda et al. [21] however had a higher figure with a $6 \%$ incidence of neurological injury; though some of their patients had pedicle screw instrumentation for spinal fusion which may have increased the complication rate. Sanderson et al. on the contrary did not record any case of postoperative neurological deficit in their series [11].

Only one patient $(2.6 \%)$ had postoperative urinary retention after removal of catheter on the first postoperative day. The patient was subsequently re-catheterized 
and weaned off urethral catheter 2 days later. Duncan et al. [24] had reported the incidence of urinary retention after spinal decompression to be $8 \%$ while Boulis et al. [25] reported an incidence as much as $38 \%$ in a large series. Boulis had suggested old age as one of the risk factors for urinary retention after decompression, this may have contributed as the only patient with urinary retention in this study was elderly.

Transient urinary and feacal incontinence were seen in two patients each (5.1\%). Duncan et al. [24] had noted a lower incidence of $2.8 \%$ in their patients. This complication may have been caused by compressive haematoma and/or undue traction during surgery on the lower lumbosacral nerve roots as had been suggested by other authors [24].

Two patients (5.1\%) developed gluteal grade 2 pressure sores postoperatively while on admission. Coincidentally the affected patients had difficulties mobilizing early out of bed; as the patients had the challenge of obesity and significant post -operative pain respectively, these may have facilitated the pressure ulcer development in the patients. The ulcers however healed with serial wound dressing.

\section{Conclusion}

In conclusion, there was significant reduction in low back and radicular pains with consequent functional improvement in majority of our patients who had posterior spinal decompression for lumbar spinal stenosis. Dura tear was noted as the commonest complication of this procedure.

\section{References}

[1] Katz, J.N., Dalgas, M., Stucki, G. and Lipson, S. (1994) Diagnosis of Lumbar Spinal Stenosis. Rheumatic Disease Clinics of North America, 20, 471-482.

[2] Niggemeyer, O., Strauss, J.M. and Schlitz, K.P. (1997) Comparison of Surgical Procedures for Degenerative Lumbar Spinal Stenosis: A Meta-Analysis of Literature from 1975-1995. European Spine Journal, 6, 423-429.

https://doi.org/10.1007/BF01834073

[3] Issack, P.S., Cunninghan, M.E., Pumberger, M. and Hughes, A.P. (2012) Degenerative Lumbar Stenosis: Evaluation and Management. Journal of the American Academy of Orthopaedic Surgeons, 20, 527-535. https://doi.org/10.5435/JAAOS-20-08-527

[4] Singh, K., Samartziz, D., Biyani, A. and Howard, S. (2008) Lumbar Spinal Stenosis. Journal of the American Academy of Orthopaedic Surgeons, 16, 171-176. https://doi.org/10.5435/00124635-200803000-00008

[5] Arnoldi, C.C., Brodsky, A.E., Cauchoix, J. and Crock, H.V. (1976) Lumbar Spinal Stenosis and Nerve Root Entrapment Syndrome. Definition and Classification. Clinical Orthopaedics and Related Research, 115, 4-5.

[6] Rajagopol, T.S. and Marshall, R.W. (2010) Understanding and Treating Spinal Stenosis. J Bone J Surg (Br), 62-B, 73-77.

[7] Bae, H.W., Rajae, S.S. and Kanim, L.E. (2013) Nationwide Trends in the Surgical Management of Lumbar Spinal Stenosis. Spine, 38, 916-926. 
https://doi.org/10.1097/BRS.0b013e3182833e7c

[8] Idowu, O.E., Adewole, O.A. and Majekodunmi, A.A. (2012) Posterior Spinal Decompression, Stabilization and Arthrodesis in Nigeria Adults. Profile and Outcome. Nigerian Meical Journal, 53, 42-46. https://doi.org/10.4103/0300-1652.99832

[9] Yukawa, Y., Lenke, L.G., Tenhula, J., Bridwell, K.H. and Riew, D.A. (2002) Comprehensive Study of Patient with Surgically Treated Lumbar Spinal Stenosis with Neurogenic Claudication. The Journal of Bone and Joint Surgery-American Volume, 84, 1954-1959. https://doi.org/10.2106/00004623-200211000-00008

[10] Gelalis, I.D., Arnaoutoglou, O.C., Christoforou, G., Lykissas, M.G. and Batsilas, I. (2010) Prospective Analysis of Surgical Outcomes in Patients Undergoing Decompressive Laminectomy and Posterior Instrumentation for Degenerative Lumbar Spinal Stenosis. Acta Orthop Traumatol. Turc., 44, 235-240.

https://doi.org/10.3944/AOTT.2010.2278

[11] Sanderson, P.L. and Wood, P.L. (1993) Surgery for Lumbar Spinal Stenosis in Old People. The Journal of Bone and Joint Surgery. British Volume, 75, 393-397. https://doi.org/10.1302/0301-620X.75B3.8496206

[12] Kwon, Y.J. (2014) Central Decompressive Laminoplasty for Treatment of Lumbar Spinal Stenosis. Technique and Early Results. Journal of Korean Neurosurgical Society, 56, 206-210. https://doi.org/10.3340/jkns.2014.56.3.206

[13] Bojanic, S., Shad, A. and Adamo, C. (2002) A New (Microscopically Assisted) Technique for Posterior Lumbar Interbody Fusion Using Posterior Spinal Elements as Bone Graft. The Journal of Bone and Joint Surgery. British Volume, 84, 334-336.

[14] Postacchini, F. and Cinotti, G. (1992) Bone Growth after Surgical Decompression for Lumbar Spinal Stenosis. The Journal of Bone and Joint Surgery. British Volume, 74, 862-869. https://doi.org/10.1302/0301-620X.74B6.1447247

[15] Postacchini, F., Perugia, G.C. and Gumina, S. (1993) The Surgical Treatment of Central Lumbar Stenosis: Multiple Laminotomy Compared with Total Laminectomy. The Journal of Bone and Joint Surgery. British Volume, 75, 386-392. https://doi.org/10.1302/0301-620X.75B3.8496205

[16] Herkowitz, H.N. and Kurtz, L.T. (1991) Degenerative Lumbar Spondylolisthesis with Spinal Stenosis: A Prospective Study Comparing Decompression with Decompression and Intertransverse Process Arthrodesis. Journal of Bone and Joint Surgery: American Volume, 73, 802-808. https://doi.org/10.2106/00004623-199173060-00002

[17] Mofidi, A., O'connor, D. and El-Abed, K. (2002) Functional Outcome Study of Patients after Surgical Decompression for Lumbar Spinal Stenosis. Effects of Concomitant Pathology. Journal of Spine Disorders and Techniques, 15, 377-383. https://doi.org/10.1097/00024720-200210000-00006

[18] Jonsson, K.A., Nemeth, G., Granath, F., Johnsson, B. and Blomquist, P. (2009) Health Related Quality of Life (EQ-5D) before and after One Year after Surgery for Lumbar Spinal Stenosis. The Journal of Bone and Joint Surgery. British Volume, 91, 210-216. https://doi.org/10.1302/0301-620X.91B2.21119

[19] Leonardi, M.A., Zannetti, M. and Min, K. (2013) Extent of Decompression and Incidence of Postoperativeepidural Haematoma among Different Techniques of Spinal Decompression in Degenerative Lumbar Spinal Stenosis. Journal of Spinal Dis orders \& Techniques, 26, 407-414. https://doi.org/10.1097/BSD.0b013e31824a03eb

[20] Andrews, N.B., Lawson, H.J. and Darko, D. (2007) Decompressive Laminectomy for Lumbar Stenosis: Review of 65 Consecutive Cases from Tema, Ghana. West African Journal of Medicine, 26, 283-287. 
[21] Okuda, S., Miyauchi, A., Oda, T. and Haku, T. (2006) Surgical Complications of Posterior Lumbar Interbody Fusion with Total Facetectomy in 25 Patients. Journal of Neurosurgery. Spine, 4, 304-309. https://doi.org/10.3171/spi.2006.4.4.304

[22] Kanafani, Z.A., Dakdouki, G.K., El-Dbouni, O., Bawwab, T. and Kanin, S. (2006) Surgical Site Infection Following Spinal Surgery at a Tertiary Center in Lebanon. Incidence, Microbiology and Risk Factors. Journal of Neurosurgery: Spine, 4, 304-309.

[23] Weinstein, M.A., McCabe, J.P. and Cammisa, F.P. (2000) Postoperative Spinal Wound Infection: A Review of 2,391 Consecutive Index Procedures. Journal of Spinal Disorders, 13, 422-426. https://doi.org/10.1097/00002517-200010000-00009

[24] Duncan, J.W. and Bailey, R.A. (2011) Cauda Equina Syndrome Following Decompression for Spinalstenosis. Global Spine Journal, 1, 15-18.

https://doi.org/10.1055/s-0031-1296051

[25] Boulis, N.M., Nian, F.S., Rodriguez, D. Cho, E. and Hoff, J.T. (2001) Urinary Retention Following Routine Neurosurgical Spine Procedures. Surgical Neurology, 55, 23-27. https://doi.org/10.1016/S0090-3019(01)00331-7 